\title{
Construyendo ciudadanía: la experiencia del presupuesto participativo en las comunas de Medellín.
}

\author{
Building citizenship: participatory budget experience in Medellin communes.
}

\author{
William Molina Merchán ${ }^{1 \star}$, Historiador, Magíster en Estética \\ ${ }^{1 *}$ Corporación Universitaria Remington. \\ Edificio Remington. Calle 51 No 51-27, Medellín, Colombia.
}

Aceptado: 14 de diciembre de 2012.

\section{Resumen.}

Las reflexiones que se presentan en este trabajo se incubaron en el proyecto: "Desarrollo social en la zona noroccidental de Medellín, (2004-2009)", realizado como experiencia de aproximación a los problemas que representan las estrategias de construcción de participación ciudadana, desde el Grupo de investigación Texturas Este análisis busca explorar las experiencias y escenarios a través de los cuales el presupuesto participativo en el rubro deportes, determina o agencia condiciones que posibilitan el mejoramiento de condiciones de vida en la Comuna Cinco de la ciudad de

Medellín. Pretende ser referente para explicar un fenómeno que en América Latina se ha venido imponiendo con fuerza en los últimos años para resolver condiciones particulares de desigualdad o de necesidades que el Estado no logró por sí mismo resolver: la vinculación de la comunidad a la solución de sus propios problemas.

Palabras clave: ciudadanía, comunas, desarrollo humano, Medellín, participación ciudadana, presupuesto participativo.

\section{Abstract.}

The reflections presented in this paper originated in the project: "Social development in the northwestern area of Medellin (2004-2009)", as an approach to the issues posed by building strategies for citizen participation. According to the Textures Research Group, this analysis explores the experiences and scenarios through which the participatory budget for sports determines conditions that enable the improvement of living conditions in Medellin's Commune Five. It aims to be a reference to explain a simmilar phenomenon that is increasing in Latin America during recent years: communities get involved in the solution of their own problems, to address inequality and needs that the state has failed to resolve.

Keywords: citizenship, communes, human development, Medellin, participation, participatory budget.

Para citar este artículo: Merchán W. Construyendo ciudadanía: la experiencia del presupuesto participativo en las comunas de Medellín. Rev Humanismo y Sociedad, 2013. Volumen 1: 64-80.

${ }^{*}$ Autor para correspondencia: William Merchán Molina. Corporación Universitaria Remington. Calle 51 No 51-27, Edificio Remington, Centro de Formación Humana.E-mail: wilca72@yahoo.es; wilcamm@hotmail.com

Revista. Humanismo.Soc. 2013; 25: 64-80. 


\section{Introducción.}

Las reflexiones que se presentan en este trabajo se incubaron en el proyecto: "Desarrollo social en la zona noroccidental de Medellín, (2004-2009)", realizado como experiencia de aproximación a los problemas que representan las estrategias de construcción de participación ciudadana, desde el Grupo de investigación Texturas Este análisis busca explorar las experiencias y escenarios a través de los cuales el presupuesto participativo en el rubro deportes, determina o agencia condiciones que posibilitan el mejoramiento de condiciones de vida en la Comuna Cinco de la ciudad de Medellín.

Pretende ser referente para explicar un fenómeno que en América Latina se ha venido imponiendo con fuerza en los últimos años para resolver condiciones particulares de desigualdad o de necesidades que el Estado no logró por sí mismo resolver: la vinculación de la comunidad a la solución de sus propios problemas.

De otro lado, se presenta como una herramienta para acercarse a la evaluación de la participación ciudadana como mecanismo político implementado efectivamente a partir de reformulaciones políticas del modelo democrático. El trabajo resulta de especial importancia particularmente para explicar en las últimas décadas, cuando las ciudades colombianas vuelven a ofrecerse a los habitantes de las zonas rurales ya no como nichos económicos y laborales, de progreso y civilización, sino como refugios de una precaria seguridad, como el lugar para defender proyectos de vida ajustados al concepto de desarrollo.

La atención del trabajo se centra en la Comuna Cinco de la ciudad por ser ella ejemplo de escenario privilegiado, por su configuración poblacional y problemática, por ser una de las zonas de mayor complejidad en cuanto a conflictos, posibilidades y proyectos. También, por constituirse como parte del centro económico y administrativo, articulador de las decisiones políticas y escenario donde se han diseñado los llamados proyectos colectivos de la ciudad. Por eso, se parte de la idea de que las representaciones colectivas en la formación de ciudadanía implican una pesquisa en los procesos sociales impulsados desde la normatividad y la formalidad y construyéndose desde lo que se ha identificado como el centro; pero también de las experiencias sociales y formas de acción colectiva realizada por los sujetos en y desde las fronteras.

Esta distinción entre centro y fronteras políticas y sociales se hace con la idea de visibilizar los más diversos y heterogéneos espacios, zonas, recodos y esferas por donde transita la formación ciudadana, muchos de los cuales han sido invisibilizados por lo que se ha posicionado como la esfera pública convencional. Pero es claro que existen transacciones, relaciones, transferencias, desplazamientos y transposición de límites entre una y otra esfera.

Resulta imperativo, entonces, aclarar que la reflexión sobre las fronteras asocia este concepto con mundialización, globalización, región, límite, multiculturalidad, otredad, identidad y diferencia; no sorprende tal referencia en la coyuntura actual de reconfiguraciones territoriales y de intensos flujos migratorios en los que las fronteras, internas adquieren relevancia, así como tampoco lo es que algunos discursos (o estudios) acentúen el carácter político de las mismas, mientras otros buscan resaltar otra dimensión como la cultural. Este último es el espacio de análisis del trabajo que se desarrolla aquí.

Cuando se aborda la formación de ciudadanía desde el "centro" estamos interpelando los procesos de deliberación pública, aquellos que -inspirados en la Constitución Política de 1991 y en los lineamientos de la Política Urbana- se han propuesto construir la "Ciudad de Ciudadanos" y promover la participación colectiva. Interesan, entonces, un proceso que en Medellín se ha convertido en puntal desde el cual se pretende construir proyectos colectivos de ciudad y consolidar un ideal de ciudadano: el Presupuesto participativo. Proyecto de ciudad que ha pretendido conseguir una "ciudad competitiva", una "ciudad educadora" y una "ciudad incluyente", según quedó establecido en el Plan Estratégico para Medellín y el Área Metropolitana, el programa Cuidad Educadora y los procesos de Planeación Zonal.

Así, en un primer momento se desarrollan teóricamente los elementos necesarios para el abordaje de la participación ciudadana y el presupuesto participativo, mientras en los capítulos posteriores se dará cuenta de la aplicación de los instrumentos metodológicos desde los cuales se confrontan la teoría y la práctica, entrevistas, a líderes comunitarios y actores políticos quienes han definido y orientado la implementación 
de mecanismos de acción buscando el mejoramiento de las condiciones de vida de la comunidad para, en un último apartado, llegar a conclusiones y formular propuestas.

\section{Construyendo ciudadanía.}

La hipótesis de trabajo sobre la cual se trabaja, se pregunta por la relación entre la inversión en presupuesto participativo para la cultura y el deporte y las dinámicas de construcción de ciudadanía en la comuna cinco e Medellín. La propuesta que se desarrolla en éste trabajo está relacionada de manera directa con la preocupación que a nivel regional, nacional y latinoamericano se viene manifestando en las últimas décadas; aun así, se procura mantener la atención sobre experiencias propias de la ciudad de Medellín.

La línea concreta de investigación en este sentido busca, siguiendo a Luis Alarcón Meneces, (ALARCÓN Meneces, 2008) en: a) comprender la conformación de la ciudadanía en las formas, tiempos y ritmos de las luchas urbanas y ciudadanas por el reconocimiento del derecho a la ciudad, b) explicar los condicionamientos e interacciones conflictivas con los modelos de urbanización que agencian las políticas urbanas, sociales y culturales. Ambos procesos, son de construcción mutua, aunque desigual, de las relaciones entre el Estado y la sociedad civil, y alguna oportunidad para la democracia.

\section{La democracia participativa.}

Después de una década de consagración constitucional de la democracia participativa, las esperanzas puestas en ella para "la construcción de un nuevo país" parecen haberse esfumado y también las promesas de cambiar la vida; de transformar las prácticas clientelistas y corruptas de la política; de conformar el ágora pública con ciudadanos virtuosos e ilustrados que dirimen dialógicamente sus conflictos y de relegitimar el Estado Social de Derecho, como expresión de un proceso de democratización en permanente expansión y crecimiento, asegurando así, la inclusión paulatina de los más diversos actores sociales y la movilización permanente de una Sociedad civil organizada con claros referentes de futuro (Corporación Región, 1993).

La comprensión sobre los procesos de configuración de democracia y de la actitud del ciudadano que se organiza y promueve alternativas de desarrollo para su comunidad pasa por comprender la innovación y la resistencia, las continuidades y las rupturas, el desfase en el ritmo de las diferentes dimensiones de cambio y las contradicciones no sólo entre distintos ámbitos sino entre diversos planos de un mismo ámbito. "como segmentos separados de lo social y lo cultural, acaba legitimando la visión de los pueblos de América Latina como meros reproductores y deformadores de la "verdadera modernidad" elaborado por los países del centro, impidiéndonos comprender la especificidad de los procesos, la peculiaridad de los ritmos, la diversidad de las formas, la simultaneidad de los tiempos y la diversidad de los mestizajes en que se produce nuestra modernidad política y cultural" (Barbero, 1996, pág. 50). Y, por supuesto, también nuestras democracias y nuestras ciudadanías.

El discurso sobre la democracia participativa enunciado en 1991 no estuvo exento del clima político reinante en ese momento y se inscribió, de manera cuasi natural, tanto en los propósitos de cambio político enunciados por los nuevos actores (jóvenes universitarios, intelectuales, miembros de las O.N.G. y gentes provenientes de varios proyectos de la Izquierda radical) ${ }^{1}$ como en la ola de movilización social que hizo posible derrotar la ortodoxia legalista y convocar una Asamblea Nacional Constituyente (Fals Borda, La Grieta de la Democracia y la participación en Colombia, 1998, págs. 65 - 74).

Los referentes sobre los cuales giraba la identificación del momento político eran: la percepción de las gentes era la de caos, la de derrumbe institucional y crisis moral; la de estar al borde del abismo o al final

\footnotetext{
${ }^{1}$ Ver al respecto: Fals Borda, Orlando “Democracia Participativa y constituyente” En Revista Foro \#13 Bogotá Octubre 1990 pp23 -29; Velásquez Fabio, "Una democracia participativa para Colombia" En Revista Foro \#16 Bogotá Diciembre 1991 pp. 60 - 73; Santana, Pedro. "Movimientos Sociales, Democracia y Poder Local” En: Democracia y Sociedad Nora Segura de Camacho (compiladora) Bogotá cidse - Fescol 1988 pp. 49 79; Borja Jordi. "participación Ciudadana en la década de los ochenta y principios de los noventa" En: Sánchez G. Ana Lucía (Editora) Procesos Urbanos contemporáneos. Bogotá. Fundación Alejandro Ángel Escobar 1995 PP. 87 - 136.
}

Revista. Humanismo.Soc. 2013; 25: 64-80. 
de un camino sin retorno que ameritaba acciones contundentes y cambios significativos y drásticos para retomar el rumbo perdido en algún momento de la vida colombiana; (Leal Buitrago, Al filo del caos, 1990) pero a esa percepción de caos se oponía la estrategia de cambio constitucional, como la alternativa de un nuevo orden que se imaginaba democrático y se deseaba pluralista, tolerante y descentralizado, con mayor capacidad para gestionar las múltiples demandas sociales desatendidas o ignoradas durante décadas.

La necesidad de configurar procesos de organización y participación y sus derechos no habla únicamente de la estructura formal de una sociedad, indican, además, el estado de la lucha por el reconocimiento de los otros como sujetos con intereses válidos, valores pertinentes y demandas legítimas. De manera que, reconduciendo el planteamiento de Néstor García Canclini, (García Canclini, 1995) los derechos deben ser conceptualizados como "principios reguladores de las prácticas sociales", ellos posibilitan y deben incentivar las conductas y practicas ciudadanas, aun aquellas que no se establecen en el orden jurídico; se tr5ata, con ello de hacer participes las subjetividades en la apropiación de los roles particulares del ciudadano en la sociedad promoviendo la interpretación y comprensión, el lugar relativo de estas prácticas dentro del orden democrático.

Los referentes sobre los cuales se movía una opinión pública difusa pero asustada y esperanzada al mismo tiempo, le otorgaron a la Carta Constitucional un carácter definitivamente Fundacional; se trataba de cerrar un ciclo de fallas estructurales (Fals Borda, La Grieta de la Democracia y la participación en Colombia, 1998, pág. 36) y de reformas importantes pero desagregadas e inorgánicas, para abrirle paso al Nuevo País, que según pensaban sus principales impulsores, no acababa de nacer por ausencia de reconocimiento institucional pero que pugnaba por inclusión, representación y participación activa en los destinos públicos.

Un nuevo comienzo que más que a la armazón de instituciones y definiciones jurídicas que le diesen cuerpo al Régimen Político y definieran - por la vía normativa - derechos, libertades y controles; es decir, más que a una constitución con sus propias posibilidades y limitaciones, se apelaba a algo más profundo y contundente, a un pacto social, donde el constituyente primario, fundase un orden político nuevo y esencialmente distinto al anterior o, como se decía en la época, un nuevo país, cuya imagen de futuro se diseñó sobre referentes épicos, utópicos y salvadores.

Si bien eran muchos y muy distintos los asuntos que pretendían transformarse y los campos en los cuales se intentaba intervenir, la narrativa que acompañó este pacto fundacional se fue configurando en torno a la democracia participativa; esta fue vista " como la clave y el hilo conductor de la Carta constitucional" (Santana, Movimientos sociales, democracia y poder local, 1988, pág. 74) o como " un destello salvador de la Nacionalidad amenazada, como una salida adecuada para todos los maltrechos aparatos estatales de la democracia colombiana pretendiendo cerrar así, una vez más, dos de las grietas políticas más grandes y antiguas de la Nación: la política administrativa y la de la violencia (Fals Borda, La Grieta de la Democracia y la participación en Colombia, 1998, pág. 31).

Paul Ricoeur ofrece elementos interesantes para estudiar cómo se fue conformando la trama, por medio de la cual, acontecimientos singulares y dispersos; propósitos de cambio referidos a esferas sin aparente conexión y eventos episódicos ocurridos en diversos tiempos históricos, fueron "puestos en intriga" (Ricoeur, 1998, págs. 80 - 113 y 13 - 1390) como dice el autor, trama e intriga mediante las cuales se le confiere unidad e inteligibilidad a lo heterogéneo, integrándolo en una historia, en una narración plena de metáforas vivas, a través de la cual pueden surgir nuevos sentidos sobre lo que se escucha o se lee; esta experiencia de totalización posibilitada por la trama y la intriga, es lo que, según Ricoeur permite recoger el pasado, diseñar el presente y establecer un horizonte de futuro al cual el autor denomina la espera; es decir, lo que se espera que ocurra de acuerdo con la manera en la cual se construyeron la trama y la intriga.(Ricoeur, 1998, pág. 132).

La democracia despolitizada y sin partidos, también parece adecuase mejor a aquellas fuerzas nuevas que irrumpieron en el espacio público durante la coyuntura constitucional del noventa y uno y que hicieron suya la bandera de la democracia participativa; estas fuerzas volátiles como las llama Marco Palacio, (Palacios, 1996)

"no lograron conformar nuevos partidos con capacidad de disputa electoral ni enunciar programas con claros 
perfiles ideológicos, ni reinventar nuevas formas de hacer política diferenciándolos del viejo bipartidismo y los mantuviese en el horizonte nacional; por el contrario, se refugiaron en los mundos de las localidades y los municipios, más idóneos para la participación y entraron en tratos, en contratos y en alianzas con los más heterogéneos y diversos actores políticos pero sin poseer las destrezas y habilidades requeridas para moverse en mercados electorales abiertos que empezaban a ser colonizados por actores armados y delincuenciales de diferente signo" (Palacios, 1996).

El clientelismo como práctica fortalecida en los esquemas políticos determinó los resultados negativos de la experiencia $y$, por el contrario, produjo consecuencias en un sentido doble; una parte de los actores fue cooptado por el clientelismo, mientras otros tomaron distancia del universo partidista, del mundo público y de la política, optando por un reforzamiento de lo puramente societario, que podríamos llamar preconstitucional; las estrategias participativas que aún subsisten, parecen haberse refugiado en los escenarios tradicionales donde los movimientos sociales y las organizaciones comunitarias se habían hecho fuertes desde los años setentas; ${ }^{2}$ quizá por eso, las evaluaciones, fragmentarias y parciales, sobre el devenir de la democracia participativa llegan a conclusiones bastante pesimistas.

La Ley 134 que reglamentó la democracia directa y participativa cubrió espacios nuevos y creó instituciones novedosas en las dos esferas de acción ciudadana; la propiamente política y la de gestión institucional; la acción en la esfera política, hace referencia a las maneras de incidir en el poder institucional a través de formas de democracia directa, como los plebiscitos, los referendos, las consultas populares, la conformación de movimientos o partidos con vocación electoral, la presentación de iniciativas ciudadanas en las corporaciones públicas entre otras; Este propósito de incidir en el poder institucional también se expresó a través de una combinación entre democracia directa y descentralizada, orientada hacia la vida regional y local mediante mecanismos tales como la revocatoria del mandato de gobernadores y alcaldes, la vigilancia y el control de las instancias públicas y la elaboración de planes de desarrollo (García Villegas , págs. 53 - 99) 3

En la vertiente de la gestión pública, se incluyen iniciativas muy amplias y complejas, van desde la participación en las juntas directivas de las empresas prestadoras de servicios públicos y sociales, hasta la conformación de las Juntas administradoras locales (JAL), pasando por una diversidad de espacios y actividades de muy distinto carácter y relacionados con la puesta en acción de políticas sectoriales orientadas hacia los jóvenes, las mujeres, los grupos étnicos subordinados, los trabajadores y campesinos; participación muchas veces promovida y organizada desde las instituciones públicas, más con el ánimo de respetar el mandato constitucional que con la intención de propiciar el acercamiento orgánico con el mundo de lo social. ${ }^{4}$

En la vertiente propiamente política es donde se hacen las evaluaciones más negativas y las previsiones más pesimistas; muchos de estos mecanismos de participación no han sido utilizados por los ciudadanos; cuando han acudido a ellos no han tenido la suficiente convocatoria ni han conseguido las metas propuestas; fracasos asignados, bien a la manera como quedaron reglamentadas por la ley, a la manida ausencia de cultura política y ciudadana o al escalamiento de la guerra; lo cierto del caso es que al cabo de diez años "parece haber más espacios abiertos de participación que ciudadanos para ocuparlos"5

En la variante que tiene que ver con la gestión pública, los resultados son paradójicos, aunque es bueno señalar que los referentes empíricos son

\footnotetext{
${ }^{2}$ Ver entre otros: Fals Borda Orlando. "El Papel Político de los Movimientos Sociales" En: Revista Foro\#11 Bogotá1996 pp 64 - 74; Archila Mauricio:" Tendencias Recientes de los Movimientos Sociales” En: En Busca de la estabilidad perdida. Actores Políticos y Sociales en los años noventa. Bogotá Tercer Mundo Editores 1995.

${ }^{3}$ Ver: García Villegas Mauricio. Óp. cit PP53 - 99

${ }^{4}$ Dada la dificultad de contar con estudios empíricos para diferentes municipios nos vamos a referir fundamentalmente a la ciudad de Medellín: ver: Fernández A. Rubén et al "Visión Panorámica de la Participación Ciudadana en la Ciudad de Medellín" Medellín. Corporación Región. 2000 (s.e.) Mimeo. P4

${ }^{5}$ Fernández A. Rubén Et all op cit P3
}

Revista. Humanismo.Soc. 2013; 25: 64-80. 
insuficientes, dado el predominio de lo regional y lo local así como la pluralidad de campos en los que estas formas participativas de gestión se desenvuelven sin embargo, al parecer los actores sociales que encarnan la participación en la gestión pública han seguido uno de estos tres caminos:

1. La cooptación por las dinámicas clientelistas y armadas

2. La vacuidad o la irrelevancia de su presencia en los aparatos de gestión; los actores de la participación están allí pero sin llevar una representación clara, sin propósitos específicos y sin capacidad real para incidir en las decisiones administrativas que allí se toman

3. La artificialidad y el formalismo, resultantes de convocatorias gubernamentales ordenadas por la ley, sin correspondencia con demandas sociales de origen ciudadano; es decir con un propósito que venga de lo social, tales como las juntas municipales de educación, los consejos de política social, los comités de participación comunitaria en salud o los centros de desarrollo comunitario (en Medellín) ${ }^{6}$ estas convocatorias ordenadas por la ley y sin la demanda social correspondiente, terminan por ser un remedo, una parodia del sentido de la participación. ${ }^{7}$

Por fuera de los espacios señalados por la Constitución política y sin ser ilegales, es dónde se advierten mayores acciones de comportamientos que reivindican espacios de acción social. No se reclama participación del Estado en la construcción y apoyo para la organización, es más, se trata de manifestaciones espontaneas de iniciativa social y popular con las que se procuran alternativas que recurren a instituciones y al trabajo colectivo con las que se resuelva la salud, empleo, vivienda y educación. El trabajo colectivo barrial que deja ver la iniciativa de líderes comunales cobra gran importancia. En cada uno de los casos se puede identificar de fondo una oposición clara a las prácticas políticas tradicionales, al cobro de impuestos por valorización y la lenta espera de construcción de obras que comprometen, en buena medida las condiciones reclamadas por las comunidades y la insatisfacción que reclaman quienes se vinculan a formas diversas de violencia; se fortalecen así las comunidades de paz, los movimientos sociales, los pactos de convivencia, la reivindicación por el derecho a la vida y en contra del secuestro, las desapariciones y a favor de la neutralidad activa.

De ésta manera, la democracia participativa se convierte en el punto de encuentro de las expectativas, discursos y temas de urgente resolución que la Constitución Política intenta resolver a través de los mecanismos de participación institucionalizados; los nuevos instrumentos que se legitiman son depurados por el legislativo y adoptados de manera inmediata por las comunidades por tres vías distintas: lo comunitario, el liberalismo y el espacio legal.

De la estrategia referida surge la ciudadanía activa, la figura del ciudadano y de sus derechos no como un simple imaginario, sino sustentado en procesos y proyectos que se realizan y depuran, que recogen propuestas y aspiraciones antes vinculadas al espacio comunitario y ahora puestas en el ámbito del reconocimiento, la participación política, la inclusión y los derechos diferenciales que, además incorporan términos como la dignidad, la individualidad la necesidad de superar la pobreza, las desigualdades sociales la explotación económica y, por supuesto, todo ello mediante la legitimación de la protesta pública.

De esta imbricación de propósitos, actores y lenguajes políticos fue surgiendo un tercer lenguaje, cercano al viejo republicanismo ${ }^{8}$ de hondas raíces en Colombia, ${ }^{9}$ centrado en la imagen del ciudadano virtuoso y el ciudadano ilustrado; Por lo primero, el ciudadano imaginado sería tolerante, respetuoso de la diferencia, pluralista, dispuesto a discutir sus diferencias sin llegar a la agresión física y de suscribir, con otros, mínimos acuerdos éticos para la convivencia.

\footnotetext{
${ }^{6}$ Fernandez A. Rubén et all Op Cit P 10.

${ }^{7}$ Ibíd.

${ }^{8}$ Colom G. Francisco O. Cit P $79-84$.

${ }^{9}$ Ver al respecto: Palacios Marco “La gobernabilidad en Colombia Aspectos Históricos” Op Cit Pp13 - 14.
} 
Este ciudadano virtuoso ${ }^{10}$ no buscaba solamente el logro de sus intereses económico - corporativos o ganancias personales y privadas; por el contrario, tendría espíritu público, tal como lo pensaban los republicanos, este ciudadano virtuoso era consciente de sus derechos pero también de sus obligaciones y deberes que lo convocaban a respetar la ley, a pagar los impuestos, a participar electoralmente, a defender el Estado de Derecho y a desarrollar acciones propositivas y no disruptivas en la esfera pública: no es extraño entonces que en algunos de los ámbitos participativos post constitucionales se hiciese muy popular una consigna que llamaba a "cambiar la protesta por la propuesta".

Por lo segundo, el ciudadano debería ser ilustrado, ${ }^{11}$ poseer cultura política, conocer sus deberes y sus derechos, saber de la Ley y de constitución así como de los recursos institucionales a los que podría apelar si sus libertades o garantías le eran conculcadas; en fin, un ciudadano con formación política que lo habilitase para actuar en público y deliberar, junto con otros ciudadanos, sobre los asuntos de competencia del común.

De allí que la cultura política y las pedagogías cívicas se convirtiesen en uno de los campos de acción privilegiados para las ONG's y al lado de ellas los espacios de formación, capacitación e información sobre espacios de educación política que desde seminarios y talleres verán y harán posible la aparición de distintas publicaciones, juegos, cartillas y manuales que incentivan y orientan a la reivindicación, desarrollo y participación del ciudadano en la construcción de propuestas de intervención social activa mediante el trabajo que se sustente en los instrumentos políticos que abre la Constitución. El público objetivo de las publicaciones y estrategias de formación no excluía a nadie, los jóvenes se reconocen en ellos como sujetos activos y propositivos, las mujeres cobran validez real, la niñez se vuelve determinante, la pobreza se convierte en discurso legitimador, los distintos actores sociales, algunos de los cuales recién se incorporan a la legalidad, provenientes del conflicto, así como representantes del Estado y líderes comunales, aúnan esfuerzos que se van a enfrentar a la actitud históricamente apática de los sectores populares para reunirse en pos de un mismo objetivo de beneficio común, actitud que se sustenta en el sometimiento a prácticas de terror, al desconocimiento de derechos sociales y humanos, a intimidaciones y a conflictos irregulares, todo ello en el marco de prácticas clientelistas que se intentaba superar con la nueva Constitución.

El repertorio discursivo neo republicano y el propósito de formar ciudadanos virtuosos e ilustrados, sigue siendo un horizonte de futuro válido para la sociedad colombiana que además recoge una tradición con mucha fuerza en la historia del país, donde los "convivencialistas"12 han tenido una significación bien especial; lo que se pretende señalar aquí es que las reivindicaciones señaladas hicieron más visibles la necesidad de despolitizar la democracia y los actores sociales procurando espacios de neutralidad que restringieran las tradicionales formas de clientelismo que hicieron posibles las contradicciones discursivas, sociales y económicas que ahora se pretendían superar. La expectativa se centró en no reclamar, más bien, en aportar soluciones que pusieran de manifiesto la urgente necesidad de reconocer la posibilidad de superar los problemas sin dejar de lado a quienes se beneficiaban o desconocía -al menos de manera frontal - con ningún actor o proyecto social y en aras a fortalecer identidades holísticas, omnicomprensivas y abstractas como aquellas de "la sociedad civil" o el "espacio público", deja en un segundo plano y medio ocultas identidades más concretas; las clasistas por ejemplo, las económico - sociales o las ideológicas en torno a las cuales se anudan las identidades concretas de los ciudadanos realmente existentes.

Del espacio desarrollado en torno a los ciudadanos sin política, ese espacio geométrico y plano, se evidenciaron los asuntos urgentes y fundamentales en que se habría de intervenir: generación de empleos, lucha contra

\footnotetext{
${ }^{10}$ Ver Uribe de H. María Teresa "De la ética en los tiempos modernos o del retorno de las virtudes públicas" En: estudios Políticos \#2 Medellín. Julio dic 1992 pp. 7 - 25.

${ }^{11}$ Restrepo R. William. "Derechos Humanos. Cultura Política y ciudadanía" En: Estudios Políticos \# (6 - 7) Medellín. Enero - Julio de 1996 pp. $149-158$.

${ }^{12}$ Ver Palacios Marco. Óp. Cita P 13 y Gutiérrez Francisco: Óp. cit P 51.
} 
la pobreza, desigualdad económica y social, las condiciones de trabajo y remuneración, propiedad de la tierra, condiciones de vida del campesinado y las comunidades marginales, todo ello en el marco de la globalización, el neoliberalismo y los desafíos propios del nuevo orden mundial.

De esta manera, el discurso sobre la ciudadanía que en su concepción filosófica entraña un contenido esencialmente político, libertario, igualitarista y sobre todo emancipador, perdió sus aristas transformadoras más agudas y se convirtió en un repertorio de fórmulas al uso para políticos en trance electoral o para funcionarios públicos que prefieren ocuparse del ciudadano virtuoso e ilustrado antes que mirar de frente los gravísimos problemas de la vida nacional.

Ciudadano virtuoso que cada vez es menos cívico, menos público y más doméstico y de la esfera privada; seudo - ciudadano no emancipado que requiere de la tutela de alcaldes y funcionarios para que le digan hasta que hora pueden salir, como deben asumir su vida íntima y que le informe a los familiares con quien anda y con qué compañías pasa sus horas libres.

El imaginario sobre el ciudadano virtuoso e ilustrado ha dificultado la identificación del ciudadano realmente existente; ese que lucha día a día contra las adversidades; que reinventa su quehacer para conseguir la subsistencia diaria; que redescubre en la práctica las maneras más adecuadas para sobrevivir y escapar del terror y la barbarie; y que aprendió de la propia experiencia y de los relatos memoriales, familiares y vecinales cuales son las formas más adecuadas para hacer política; para moverse, con cautela en la esfera pública; para ocultarse o para hacerse visible, para participar o para mantenerse en la esfera doméstica y privada; para desplazarse o para ofrecer resistencia, en suma, el ser y el hacer de los ciudadanos o al menos de los que pugnan por serlo, no se ajustan a los imperativos de la moral cívica pero de allí no se puede concluir su no existencia o que carezcan de virtudes y de sabidurías. La democracia participativa deja de ser épica, mesiánica y salvífica, hoy se la mira con saludable incertidumbre y con un realismo que hace posible identificar sus límites y posibilidades, una actitud que permite ampliar sus horizontes sin desconocer que cada una de las comunidades vive sus procesos de manera particular y en razón de experiencias propias producto de sus problemas, historias y expectativas.

La integración social presenta, entonces, dos dimensiones importantes: a) aquella que hace referencia a las políticas urbanas como políticas sociales $y, b)$ aquella que expresa luchas de participación por el derecho a la ciudad. En el primer sentido, la experiencia de urbanización asociada a la industrialización en América Latina, viabilizó formas de desarrollo económico y constituyó modalidades de conformación de las sociedades latinoamericanas, impulsando y haciendo posibles procesos de integración social. Los mecanismos de su viabilización han sido: "la ampliación de la ciudadanía en el plano político y la ampliación de la integración social a través de la educación, la salud, la vivienda, la seguridad social, entre otros". ${ }^{13}$ Pueden interpretarse, además, las relaciones existentes entre lo urbano y social, sus posibilidades y discursos, desde el derecho a los espacios propios de la ciudad, en tanto las comunidades y sectores reivindican con su acción la necesidad de espacios dentro del imaginario de lo urbano que los incluyan, que dignifiquen sus condiciones y multipliquen su posibilidades. La ciudad se convierte en ideal realizable de inclusión, dignidad, desarrollo y equidad, posible siempre y cuando hacia ella se orienten-no a los individuos- las directrices e intereses del Estado.

La democracia participativa y directa dejó de ser el centro iluminador de la vida política; la clave que abría toda las puertas y solucionaba todas las fracturas, desigualdades e inequidades de la vida social para encontrar su propia esfera de acción, tal vez más restringida y necesitada de complementariedad con formulas como la representación política; es evidente que la estrategia ha dado resultados que se manifiestan en la multiplicación de movimientos sociales y formas de agremiación y organización de comunidades que cobran mayor validez y peso en la generación de espacios de veeduría, participación y desarrollo de propuestas democráticas efectivas y reconocidas.

En suma, los procesos de secularización y descentramiento de la democracia participativa, aunque

\footnotetext{
${ }^{13}$ Enzo Faletto. "Politica social, desarrollo y democracia. La función del Estado en América Latina". Revista Foro No 23, Santafé de Bogotá, Foro Nacional por Colombia, abril de 1994, p. 6.
} 
han traído desesperanza, frustración y desencanto, son saludables y benéficos para el devenir de la vida política colombiana en la medida en que "descargan" esta forma de acción política de expectativas que van más allá de sus posibilidades.

\section{El presupuesto participativo.}

El Presupuesto Participativo se implementó como la iniciativa que desde las instituciones de gobierno hacía posible el análisis de caminos posibles con los que se articulara la democratización de la gestión pública a las necesidades reales manifiestas por los distintos sectores y comunidades para la elaboración de políticas públicas y la inversión de recursos en obras consideradas como prioritarias y en consenso; además, la iniciativa permitía la veeduría directa de la ciudadanía a las obras e inversiones que les comprometían.

Como se afirma en el informe sobre participación ciudadana realizado para Brasil (MAIRAL, 1998), "Una de las características más importantes para entender esta iniciativa como experiencia clave en este debate, es el desarrollo institucional de un proyecto que partiendo de cortas experiencias en Montevideo y Porto Alegre (Brasil)". Con la puesta en marcha de este proceso, se apostó por la potenciación de una democracia participativa permitiendo a la ciudadanía el proceso de toma de decisiones. En tal sentido buscó la potenciación de la participación directa de la población en la elaboración y ejecución del presupuesto municipal, dando prioridad a los programas a presupuestar desde las necesidades directas de la ciudadanía comprometida en el proceso.

Para el caso específico de la ciudad el programa fue creado en 2004 por la Alcaldía de Medellín como un proceso de participación ciudadana (Acuerdo Municipal No 43 de 2007, "Por el cual se crea e institucionaliza la planeación local y el Presupuesto Participativo en el marco del Sistema Municipal de Planeación y se modifican algunos de sus artículos", 1996). Así, El gobierno municipal reservaba una parte de los recursos municipales para que su destinación sea decidida por todos los ciudadanos mayores de 14 años.

¿En qué consiste?.

El presupuesto participativo contempla la participación (Acuerdo Municipal No 43 de 2007, "Por el cual se crea e institucionaliza la planeación local y el Presupuesto Participativo en el marco del Sistema Municipal de Planeación y se modifican algunos de sus artículos", 1996) ${ }^{14}$, tanto de la comunidad como de la administración municipal, para que juntos decidan cuáles son las necesidades de su comuna y cómo utilizar de la mejor manera una parte de los recursos municipales. 435 mil millones fueron asignados al programa en el cuatrienio 2008-2011 del Alcalde, con el objetivo de aportarle a la Institucionalidad Democrática y a la Participación Ciudadana en Medellín:

El procedimiento establecido para el funcionamiento y la formulación ${ }^{15}$ del Presupuesto Participativo según quedó establecido, comprende de manera general las siguientes fases:

1. Asignación del presupuesto anual para cada comuna y corregimiento en el marco del Plan Operativo Anual de Inversiones de la vigencia respectiva.

2. Realización de las asambleas barriales y veredales para identificar problemas y oportunidades de cada barrio o vereda. Cada Asamblea elegirá un(a) delegad(a) al Consejo Comunal o de Corregimiento, a razón de, máximo, uno (1) por cada 25 votantes en la Asamblea barrial y uno por cada 15 votantes en la Asamblea veredal.

3. Realización de Consejos Comunales y de Corregimientos en las distintas fases del proceso: Diagnóstico, priorización, aprobación del presupuesto participativo, monitoreo y seguimiento a la ejecución.

4. Refrendación de la decisión del Consejo Comunal y de Corregimiento mediante resolución de la Junta Administradora Local y entrega al Departamento Administrativo de Planeación.

\footnotetext{
${ }^{14}$ Acuerdo Municipal No 43 de 2007: ARTICULO 63․ DEFINICIÓN DEL PRESUPUESTO PARTICIPATIVO: Es una herramienta de gestión participativa de los recursos de inversión asignados a las comunas y corregimientos que hacen parte del presupuesto anual del Municipio.

${ }^{15}$ Acuerdo Municipal No 43 de 2007: ARTICULO 64․ FORMULACIÓN DEL PRESUPUESTO PARTICIPATIVO.
}

Revista. Humanismo.Soc. 2013; 25: 64-80. 


\section{El proceso de configuración.}

El acuerdo que le da vida al presupuesto participativo (Acuerdo Municipal 047, por el cual se institucionaliza la planeación local y el presupuesto participativo en el marco del sistema municipal de planeación, 1996) deja en firme que en principio se requiere la inscripción de delegados de organizaciones sociales, comunitarias y solidarias para participar en el proceso; Con ello, se establece en el Acuerdo citado que: "todas las entidades sin ánimo de lucro, que certifiquen el trabajo constante y permanente en su respectiva comuna o corregimiento, con personería jurídica mayor a un año y con mínimo de 10 miembros, podrán inscribir un delegado o delegada al proceso, para la toma de decisiones y la priorización de iniciativas a ejecutar."

Un segundo elemento a tener en cuenta son las Asambleas Barriales y Veredales, se trata de un espacio de encuentro entre los habitantes y vecinos de cada barrio y vereda para socializar el Plan de Desarrollo Local de la respectiva comuna o corregimiento y allí identificar y priorizar necesidades concretas de la comunidad; es en este espacio donde se eligen los delegados del barrio o vereda para los Consejos Comunales y de Corregimiento que decidirán la destinación del recurso.

En ese sentido "es necesario tener en cuenta el derrotero trazado por el Plan de Desarrollo Local como herramienta de planeación, construida colectivamente por los habitantes de cada comuna y corregimiento para aportarle a su desarrollo integral, a partir de objetivos estratégicos y metas alcanzables en un tiempo determinado. Operativamente, cada comuna y corregimiento cuenta con un tarjetón de priorización de problemas y de votación, construido colectivamente entre los representantes de cada comunidad: Equipos Coordinadores (conformados por: miembros de las Juntas Administradoras Locales, un delegado o delegada de cada comuna o corregimiento elegido por la misma comunidad, un representante de Asocomunal y un delegado de cada comisión de trabajo) y por los Equipos Gestores de cada Plan de Desarrollo Local".

El tarjetón de priorización de problemas y de votación se divide así:

Listado de problemas, proyectos y necesidades específicas de cada comuna y corregimiento, ligadas directamente al respectivo Plan de Desarrollo Local, en el que la comunidad tiene la oportunidad de elegir hasta 3 opciones.

Elección de proyectos del Plan de Desarrollo Municipal, en el que la comunidad tiene la oportunidad de elegir hasta 1 opción.

Voto para la elección de delegados. En las comunas, se eligen un delegado por cada 25 participantes y en los Corregimientos, se elige un delegado por cada 15 participantes. 


\section{Seguimiento y evaluación del presupuesto.}

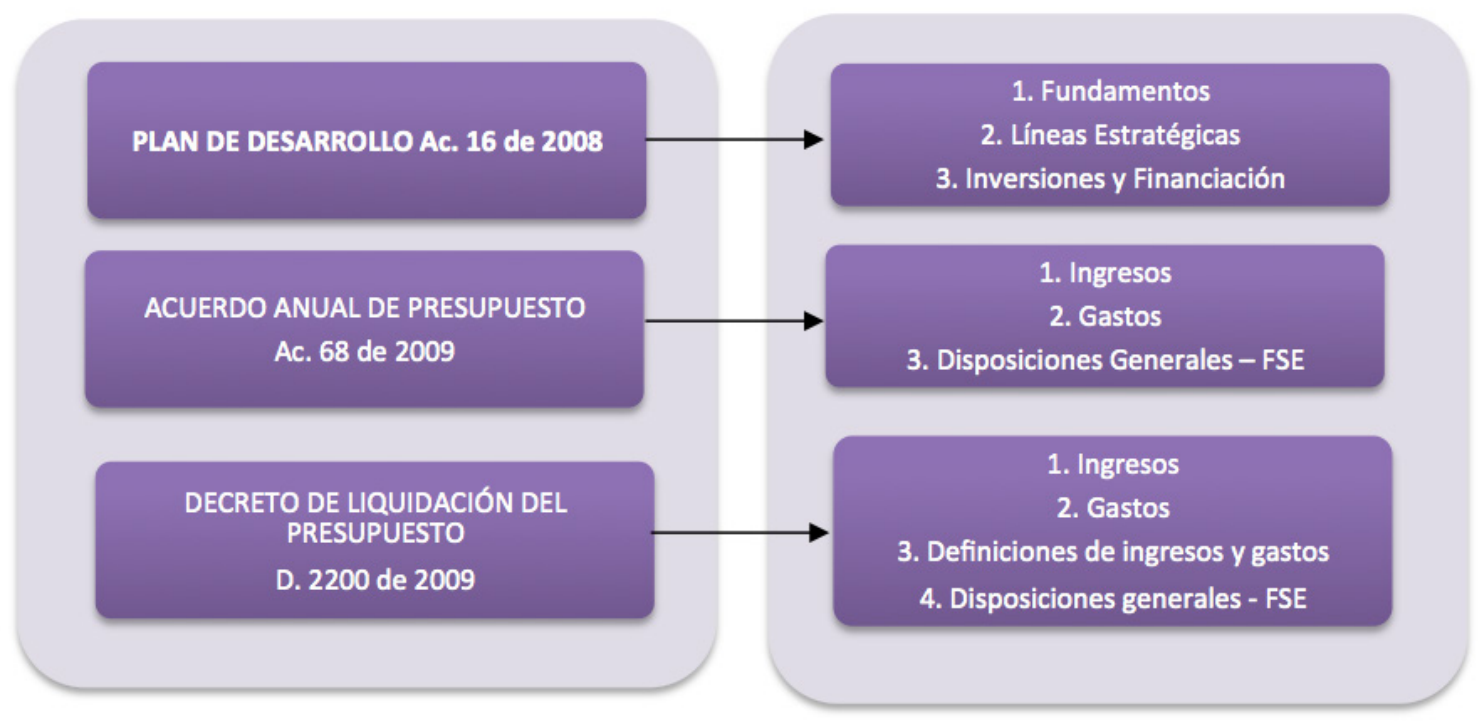

Figura 1. Normativa Vigente en el Municipio de Medellín.

El Presupuesto General del Municipio de Medellín se encuentra sujeto además al control de diversos entes o dependencias con el fin de verificar que las decisiones presupuestales se ejecuten correctamente y de acuerdo con la normativa:

\section{Control político: Es ejercido por el Concejo.}

2. Control fiscal: Lo ejerce la Contraloría General de Medellín.

3. Seguimiento financiero del Presupuesto General y de las empresas para realizar la programación y la ejecución presupuestal es realizado por la Secretaría de Hacienda.

4. Evaluación de la inversión pública y el control de resultados: está a cargo del Departamento Administrativo de Planeación.

Además de los controles al presupuesto que se pueden identificar en el Estatuto Orgánico de Presupuesto de Medellín, en la práctica, el presupuesto general está sometido a los siguientes controles:

1. Control Jurisdiccional: Es ejercido por el Tribunal competente y el Gobernador (Constitución Nacional Art. 305, numeral 10).
2. Control de la Ciudadanía: Atendiendo a lo que establece el Artículo 270 de la Carta Política: "La Ley organizará las formas y los sistemas de participación ciudadana que permitan vigilar la gestión pública que se cumpla en los diversos niveles administrativos y sus resultados".

El Municipio de Medellín institucionalizó el proceso de Planeación Local y Presupuesto Participativo en el marco del Sistema Municipal de Participación. Mediante el Acuerdo Municipal 43 de 2007 creó el Comité Municipal de Presupuesto Participativo como un espacio de coordinación para el diseño de la metodología y del Reglamento del Presupuesto Participativo.

En cumplimiento de lo mandado por el parágrafo 2 del artículo 64 del Acuerdo Municipal 43 de 2007, se conformó el Comité Municipal de Presupuesto Participativo CMPP integrado por: un integrante del Departamento Administrativo de Planeación, un integrante de la Secretaría de Desarrollo Social, un representante de cada Junta Administradora Local, un representante de cada Consejo Comunal y de Corregimiento, y por el Presidente del Consejo Territorial de Planeación o su delegado, el cual elaboró el proyecto de Reglamento de la Planeación Local y el Presupuesto Participativo de Medellín. 
El proyecto de reglamento fue diseñado y concertado ampliamente por el Comité Municipal de Presupuesto Participativo en diferentes sesiones de trabajo que tuvieron lugar los días 7 y 14 de marzo, 18, 25 y 27 de abril de 2009.

El documento Reglamento de la Planeación Local y el Presupuesto Participativo plantea una metodología mínima paraeldesarrollodelos procesos dela Planeación
Local y el Presupuesto Participativo de Medellín, que no limita la capacidad creativa o de iniciativa que tengan las Juntas Administradoras Locales y la comunidad para aplicar innovaciones metodológicas que amplíen y dinamicen la participación ciudadana.

El Alcalde es la máxima autoridad del proceso de Planeación Municipal y está facultado para reglamentarlo.
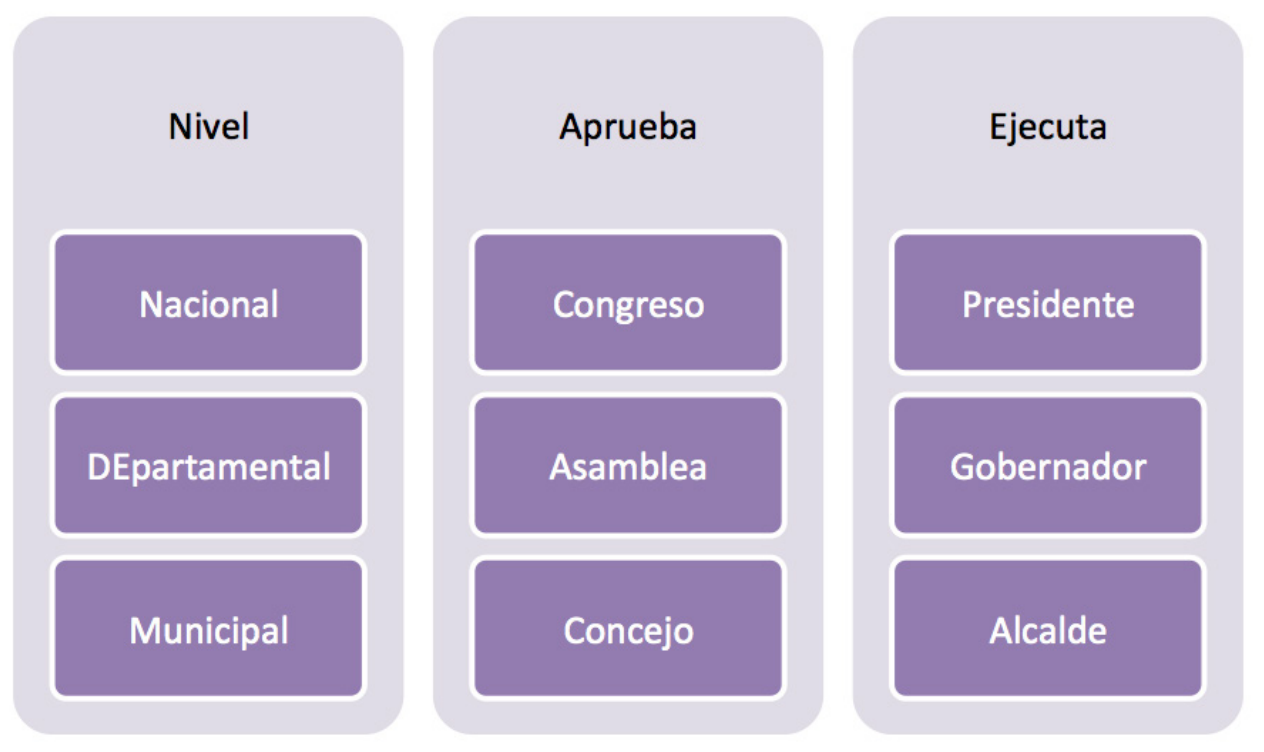

Figura 2. Dinámica presupuestal del Sector Público en Colombia.

\section{Principio de Legalidad del Gasto ${ }^{16}$.}

El Principio de Legalidad del gasto público es el núcleo rector en materia presupuestal en Colombia, nace en la Constitución Nacional y ha sido desarrollado ampliamente por la Corte Constitucional mediante varias sentencias, tales como: C-197/01, C-442/01, C-859/01, C-1249/01, T-1337/01, C-428/02, C-483/02, C-399/03, T-1135/03, C-423/05.

“...El recaudo y aplicación de los dineros estatales deben manejarse de conformidad con reglas y procedimientos predeterminados y contables, de manera que, para que una erogación pueda ser efectivamente realizada tiene que haber sido previamente decretada por ley, ordenanza o acuerdo e incluida dentro del respectivo presupuesto. Ciertamente, no se podrán hacer erogaciones con cargo al tesoro que no se encuentren previstas en el presupuesto de gastos y no hayan sido aprobadas por el Congreso, las asambleas departamentales y los concejos municipales, ni incluir partida alguna en la ley de apropiaciones que no corresponda a un crédito judicialmente reconocido, a un gasto decretado conforme a una la ley anterior, a uno propuesto por el gobierno para atender el funcionamiento de las ramas del poder público, el servicio de la deuda o a dar cumplimiento al Plan Nacional de Desarrollo". Sentencia C-428/02.

\footnotetext{
${ }^{16}$ Fuente: Artículos 345 y 346 de la Constitución Política.
} 


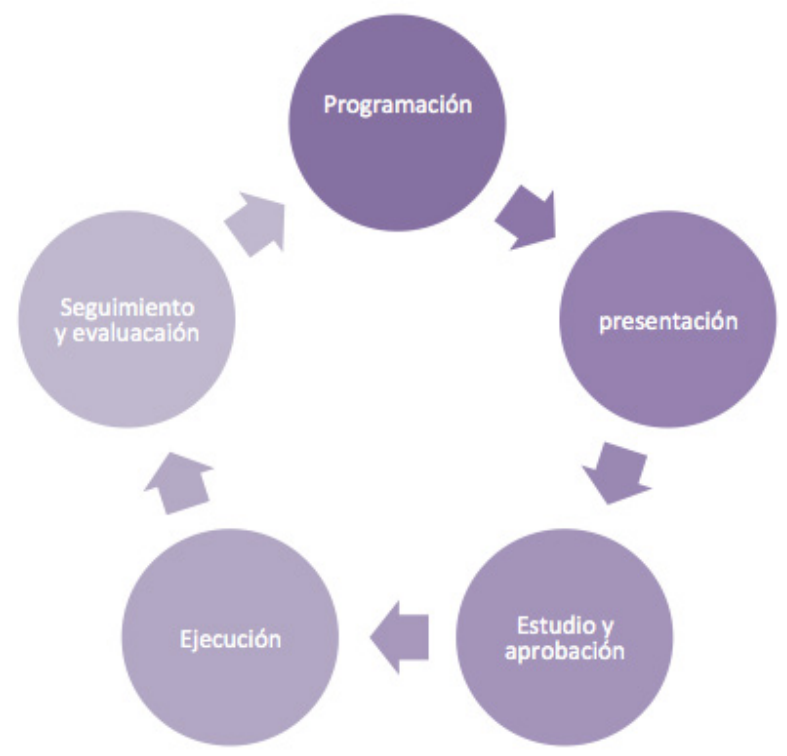

Figura 3. Etapas del Ciclo presupuestal.

El programa presenta tal grado de efectividad que año a año se fueron definiendo mayores recursos económicos para que las mismas comunidades definieran la inversión en soluciones a sus problemas más urgentes; así, como se muestra en el siguiente cuadro, comenzó a evidenciarse el buen recibo de las estrategias.

Tabla 1. Presupuesto asignado por comunas entre 2004-2008.

\begin{tabular}{|l|r|r|r|r|}
\hline Comuna o & $\begin{array}{c}\text { T asignado } \\
\text { 2004-2005 }\end{array}$ & $\begin{array}{c}\text { T asignado } \\
\text { 2005-2006 }\end{array}$ & $\begin{array}{c}\text { T asignado } \\
\text { 2006-2007 }\end{array}$ & $\begin{array}{r}\text { T asignado } \\
\text { 2007-2008 }\end{array}$ \\
\hline & & & & \\
\hline & & & & \\
\hline Popular & 6.743 .000 & 5.300 .000 & 5.890 .000 & 7.500 .000 \\
\hline Santa Cruz & 5.814 .000 & 4.500 .000 & 5.000 .000 & 7.100 .000 \\
\hline Manrique & 4.152 .287 & 4.300 .000 & 4.779 .000 & 6.900 .000 \\
\hline Aranjuez & 3.996 .000 & 4.100 .000 & 4.556 .000 & 6.600 .000 \\
\hline Castilla & 2.821 .000 & 3.300 .000 & 3.667 .000 & 5.300 .000 \\
\hline Doce de Octubre & 3.715 .000 & 4.400 .000 & 4.890 .000 & 7.100 .000 \\
\hline Robledo & 3.159 .000 & 3.700 .000 & 4.112 .000 & 6.100 .000 \\
\hline Villa Hermosa & 3.499 .000 & 3.752 .000 & 4.170 .000 & 6.200 .000 \\
\hline Buenos Aires & 2.939 .000 & 3.200 .000 & 3.556 .000 & 5.300 .000 \\
\hline La candelaria & 2.202 .000 & 2.300 .000 & 2.556 .000 & 3.700 .000 \\
\hline Laureles & 2.023 .000 & 2.023 .000 & 2.248 .000 & 3.300 .000 \\
\hline La América & 2.298 .000 & 2.500 .000 & 2.778 .000 & 4.000 .000 \\
\hline San Javier & 3.499 .000 & 3.900 .000 & 4.334 .000 & 6.500 .000 \\
\hline Poblado & 2.125 .004 & 2.125 .000 & 2.362 .000 & 3.400 .000 \\
\hline Guayabal & 2.604 .000 & 2.800 .000 & 3.112 .000 & 4.600 .000 \\
\hline Belén & 2.403 .000 & 2.600 .000 & 2.890 .000 & 4.200 .000 \\
\hline Palmitas & 603.000 & 750.000 & 949.000 & 1.440 .000 \\
\hline San Cristóbal & 1.431 .826 & 1.700 .000 & 2.148 .000 & 3.230 .000 \\
\hline AltaVista & 1.191 .855 & 1.350 .000 & 1.706 .000 & 2.560 .000 \\
\hline San Antonio Prado & 1.932 .765 & 2.400 .000 & 3.033 .000 & 4.570 .000 \\
\hline Santa Elena & 838.898 & 1.000 .000 & 1.264 .000 & 1.900 .000 \\
\hline Total & 59.990635 & 62.000 .000 & 70.000 .000 & 101.500 .000 \\
\hline & & & & \\
\hline
\end{tabular}


El Presupuesto General para 2011 presentado ante el Concejo Municipal llega a $\$ 3$ billones 300 mil millones, de los cuales $\$ 2$ billones 982 mil millones corresponden al Presupuesto Municipal. El Proyecto de Presupuesto propone que de cada peso que ingrese al Municipio de Medellín, 82.9 centavos se destinarán a satisfacer actividades de inversión como equipamientos sociales, seguridad, atención a población vulnerable, vías, entre otros; así, el 15.2\% del Presupuesto General se destinará a gastos de funcionamiento.

Además de entregarles a las comunidades la responsabilidad de su propio desarrollo en la búsqueda de respuestas a sus propias necesidades y expectativas, el Programa implementado desde el gobierno municipal cumplió con objetivos que fueron más importantes a futuro; en primer lugar, se convirtió en una escuela de identificación formación de líderes que, en el ejercicio otorgado por los vecinos, de manera espontánea, fueron descubriendo caminos de acción para aportar a las ideas y propuestas que surgían de manera desordenada y que en otro esquema de acción se hubieran perdido entre oficinas tratando de tramitar su ejecución. En segundo lugar, se logró ejecutar el mandato constitucional de vincular al ciudadano a la construcción de alternativas y respuestas a los problemas de su propia comunidad. Es claro que el proyecto no era improvisado, desde el inicio se planteó cinco tareas:

1. Fortalecimiento y desarrollo del Sistema municipal de planeación

2. Diseño e implementación del presupuesto participativo

3. Construcción y operación de un sistema de monitoreo y evaluación participativa

4. Aprendiendo del mundo: conocimiento e intercambio de experiencias exitosas de planeación, presupuesto y gestión participativas

5. Servidores públicos comprometidos con la comunidad. Su operación fue establecida en el programa de Planeación y Presupuesto Participativo.
Se trataba de un trabajo planeado de manera sistemática, que contó con un reglamento y que programó actividades anuales, así:

1. Primera fase fue la de información y diagnóstico.

2. Segunda, la construcción y priorización de iniciativas de inversión.

3. Tercera, la contratación, ejecución y seguimiento.

Las comunidades que otrora manifestaban escepticismo y desconfianza frente a estrategia innovadoras de vinculase a trabajar por las comunidades, más cuando éstas históricamente eran lugares del cacicazgo político, ha comenzado a ver en la llegada de recursos y la solución de algunos de los problemas que ellas mismas señalan, una vía de desarrollo social que, aun hay que perfeccionar y a la que deberán vincularse cada vez más sectores sociales. Porcentualmente el presupuesto participativo logró tocar asuntos diversos como se desprende de los siguientes datos estadísticos:

Obras públicas y medio ambiente (43.3\%),

Cultura, deporte y recreación (33\%),

Educación (28\%),

Convivencia y participación ciudadana (17\%),

Salud y población vulnerable (16\%),

Economía- empresarismo (10\%).

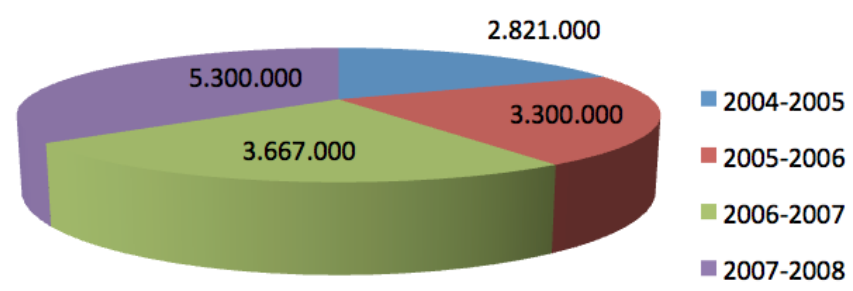

Figura 4. Inversión por años del presupuesto participativo en la Comuna 5. 
Tabla 2. Participantes por año en el PP.

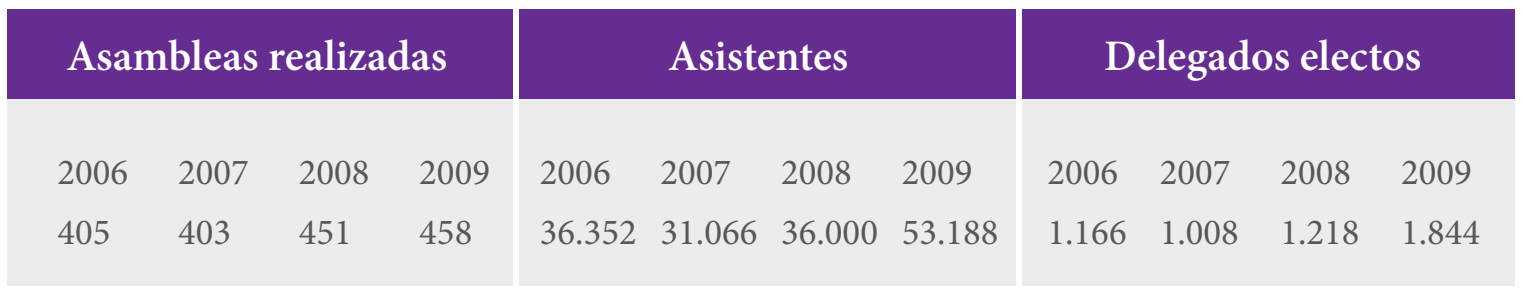

Resultados en la participación del proceso de participación en Presupuesto Participativo para el caso de Medellín ${ }^{17}$.

Los delegados representantes de organizaciones sociales, comunitarias, solidarias y los delegados electos en las Asambleas Barriales y Veredales, adquieren el compromiso de capacitarse, promover el Plan de Desarrollo Local, motivar la participación de otros ciudadanos y participar de las deliberaciones en los Consejos Comunales y de Corregimiento.

Tabla 3. Iniciativas presentadas por año al PP.

$$
\begin{aligned}
& \multicolumn{5}{c}{\text { Iniciativas presentadas por año }} \\
& \begin{array}{lllll}
2004 & 2005 & 2006 & 2007 & 2008 \\
916 & 766 & 1.042 & 1.817 & 1.819
\end{array}
\end{aligned}
$$

Escenarios de participación: son los espacios en los que la Administración Municipal socializa información general del programa, da a conocer el estado de cada Plan de Desarrollo Local y se presentan los resultados de las Asambleas Barriales y Veredales ante los delegados. Además, en ellos los delegados definen y se distribuyen para conformar las Comisiones Temáticas de Trabajo, y se distribuye el recurso asignado a cada comuna y corregimiento. Las comisiones son grupos de trabajo conformados por los delegados de los Consejos Comunales y de Corregimiento, debidamente inscritos para el respectivo año, acompañados por servidores públicos de cada una de las Secretarías encargadas de ejecutar el recurso. En ellas se analizan los temas específicos y las iniciativas de acuerdo a la comisión que pertenezcan y se elaboran propuestas o iniciativas de proyectos, a partir de los problemas identificados como prioritarios en la comuna o corregimiento. Según las características y dinámicas de cada Plan de Desarrollo Local, el Consejo Comunal o de Corregimiento define el número de comisiones y su nombre respectivo, en las que temas prioritarios deben ser trabajados, entre ellos los más importantes por su recurrencia son:

1. Protección Social: atención a la población vulnerable. 2. Educación: calidad y acceso.

3. Desarrollo económico: materialización de oportunidades.

4. Obras Públicas: mejoramiento físico y movilidad.

5. Medio Ambiente: sostenibilidad.

6. Convivencia, seguridad y participación ciudadana: inclusión.

7. Cultura: diversidad y reconocimiento de las diferencias.

8. Recreación y deporte: el sano esparcimiento como derecho; es este el rubro específico de interés de este trabajo.

\footnotetext{
${ }^{17}$ http://www.medellin.gov.co/alcaldia/jsp/modulos/I_gestion/presupuestoparticipativo.jsp Consultado el 13 de abril de 2010.
} 
El Equipo de Gestión Conformado por el número de personas que decide el respectivo Consejo Comunal y de Corregimiento, cuenta con mínimo tres (3) voceros de las JAL, el delegado al Comité Municipal de Presupuesto Participativo (CMPP), los delegados de las Comisiones Temáticas y un delegado de Asocomunal (o de las Juntas de Acción Comunal en caso de que ésta no exista); está dotado de su propio reglamento y se encarga de crear estrategias de gestión facilitando y promoviendo la articulación de los Planes de Desarrollo Local, para avanzar en la planeación y gestión del desarrollo zonal.

El Comité Municipal de Presupuesto Participativo (CMPP) se configura como el Espacio de coordinación para el diseño de la metodología y del reglamento del programa, que estará integrado por:

1. Un representante de la JAL de cada comuna y corregimiento, elegido en reunión formal de las mismas.
2. Un representante de cada Consejo Comunal o de Corregimiento, elegido en sesión plenaria.

3. El Presidente del Consejo Territorial de Planeación, o su representante.

Dos representantes de la Administración Municipal en cabeza de las Secretaría de Desarrollo Social y del Departamento Administrativo de Planeación.

De esta manera, se vincula la comunidad a la posibilidad de generar respuestas apropiadas a sus propias necesidades, este proceso es seguido de manera permanente por la alcaldía municipal en Encuentros Zonales y de Evaluación en espacios de diálogo y retroalimentación entre delegados y delegadas del proceso con el Alcalde y su gabinete, realizado en cada una de las zonas de la ciudad para presentar y valorar la gestión de la Administración Municipal en torno al Programa.

\section{Referencias}

ACUERDO Municipal 047, por el cual se institucionaliza la planeación local y el presupuesto participativo en el marco del sistema municipal de planeación, Acuerdo Municipal 043 de 2007 (1996).

ACUERDO Municipal No 43 de 2007, "Por el cual se crea $e$ institucionaliza la planeación local y el Presupuesto Participativo en el marco del Sistema Municipal de Planeación y se modifican algunos de sus artículos", Acuerdo 043 de 1996 (Concejo Municipal de Medellín 1996).

ALARCÓN Meneces, L. (11 de marzo de 2008). Historia de occidente desde la modernidad. Recuperado el 17 de novienmbre de 2011, de http://historiaoccmodernidad. blogspot.com/2008/03/lectura-no-5-formacin-de-ciudad-y. html

ALONSO Espinal, M. A. (1997). Elecciones, Territorios y Conflicto. Estudios Políticos , 135 - 144.

BARBERO, J. (1996). Comunicación y Ciudad: Sensibilidades, paradigmas, escenarios. Pensar la Ciudad. Santafé de Bogotá. Tercer Mundo Editores, Cenac, 50.

CORPORACIÓN REGIÓN. (1993). Procesos de urbanización y nuevas conflictividades sociales. Región.

FALS Borda, O. (1998). La Grieta de la Democracia y la participación en Colombia. Análisis Político No 28. Bogotá. Mayo - Agosto , 65 - 74.

GARCÍA Canclini, N. (1995). Consumidores y ciudadanos. Conflictos multiculturales de la globalización. Mexico : Grijalbo.

García Villegas, M. (s.f.).

GÓMEZ, B. (1991). Políticas estatales en el hábitat popular 1968 - 1988: El caso de Medellín. Serie Investigaciones No 15 Centro de Estudios del Hábitat Popular - Cehap. Facultad de Arquitectura, Universidad Nacional de Colombia. Medellín .

GUTIÉRREZ Sanín, F. (1999). Dilemas y paradojas de la transición participativa. Estudios políticos No 15, 46 - 49.

LEAL Buitrago , F. (1990). Al filo del caos. Bogotá: Tercer Mundo editores.

MAIRAL, P. (1998). O orçamento participativo, análise de uma experiência de gestão local participativa". Porto Alegre: Pontificia Uversidade Catolica do Rio Grande Do Sul (PUCRS). .

PALACIOS, M. (1996). la gobernabilidad en Colombia. Aspectos históricos. Análisis Político, 18. 
RICOEUR, P. (1998). Tiempo y Narración. Configuración del tiempo en el relato histórico. Tomo 1:. Madrid: Siglo XXI. Editores.

SANTANA , P. (1988). Movimientos sociales, democracia y poder local. Democracia y Sociedad, 49- 79.
URIBE de Hincapié, M. (1999). Las soberanía en Disputa. ¿conflicto de identidades o de Derechos? Estudios Políticos No 15. Medellín. Jul-Dic. , 23 - 49. 